\title{
Increased Body Adiposity and Serum Leptin Concentrations in Very Long-Term Adult Male Survivors of Childhood Acute Lymphoblastic Leukemia
}

\author{
Kirsi Jahnukainen ${ }^{\text {a, }}$ h Risto Heikkinen ${ }^{b}$ Markus Henriksson ${ }^{\text {e }}$ Sture Andersson $^{d}$ \\ Kaisa K. Ivaskag Leena-Riitta Puukko-Viertomies ${ }^{b}$ Outi Mäkitie ${ }^{c, f, i}$ \\ Divisions of a Hematology-Oncology and Stem Cell Transplantation, ${ }^{b}$ Adolescent Psychiatry and ${ }^{c}$ Pediatric \\ Endocrinology and Metabolic Bone Diseases, ${ }^{\mathrm{d}}$ Children's Hospital, Helsinki University Central Hospital and \\ University of Helsinki, ${ }^{e}$ National Supervisory Authority for Welfare and Health, and ${ }^{\mathrm{f}}$ Folkhälsan Research Center, \\ Helsinki, and IInstitute of Biomedicine, Department of Cell Biology and Anatomy, University of Turku, Turku, \\ Finland; ' Department of Women's and Children's Health, and 'Center for Molecular Medicine and Surgery, \\ Karolinska Institute and University Hospital, Stockholm, Sweden
}

\section{Key Words}

Male acute lymphoblastic leukemia survivors - Adiposity · Leptin · Adiponectin · Hypogonadism · Childhood leukemia

\begin{abstract}
Background: We evaluated the body composition and its association with hypogonadism in adult male long-term acute lymphoblastic leukemia (ALL) survivors. Methods: The cohort included 49 long-term male ALL survivors and 55 age-matched healthy controls. Fat and lean mass was assessed by dual-energy X-ray absorptiometry; blood biochemistry was obtained for adipokines and testicular endocrine markers. Results: As compared with controls, the ALL survivors (median age 29 years, range 25-38), assessed $10-$ 28 years after ALL diagnosis, had higher percentages of body $(p<0.05)$ and trunk fat mass $(p<0.05)$, and a lower body lean mass $(p<0.001)$. Survivors had significantly higher levels of leptin and adiponectin and lower levels of insulin-like growth factor-binding protein 3 . Body fat mass and percent fat mass correlated with serum leptin and sex hormone-binding globulin (SHBG) levels. Altogether, $15 \%$ of the ALL survivors and $9 \%$ of age-matched controls were obese (BMI $\geq 30$ ).
\end{abstract}

Obese survivors more often had hypogonadism, had received testicular irradiation, and needed testosterone replacement therapy compared to nonobese survivors. Conclusion: At young adulthood, long-term male ALL survivors have significantly increased body adiposity despite normal weight and BMI. Potential indicators of increased adiposity included high leptin and low SHBG levels. Serum testicular endocrine markers did not correlate with body adiposity.

๑) 2015 S. Karger AG, Basel

\section{Introduction}

Long-term survivors of childhood acute lymphoblastic leukemia (ALL) have an increased prevalence of obesity $[1,2]$ and physical inactivity $[3,4]$ as well as a significantly elevated risk for cardiovascular disease $[5,6]$ and related mortality [7] in the years after treatment. In particular, abdominal obesity, which is known to be a risk factor for diabetes and cardiovascular diseases, has shown increased prevalence among ALL survivors [8]. Cranial radiotherapy (CRT) during ALL treatment has been implicated as a potential cause for excess weight gain among survivors $[9$,

\section{KARGER 125\%}

(c) 2015 S. Karger AG, Base

$1663-2818 / 15 / 0842-0108 \$ 39.50 / 0$

E-Mail karger@karger.com

www.karger.com/hrp
Dr. Kirsi Jahnukainen

Division of Hematology-Oncology and Stem Cell Transplantation

Children's Hospital, Pl 281

FI-00029 Helsinki (Finland)

E-Mail Kirsi.Jahnukainen@ @i.se 
10]. Although the mechanism by which CRT leads to obesity is unknown, hypothalamic damage leading to growth hormone deficiency or leptin insensitivity, or both, have been suggested as causative factors $[9,11]$. Zhang et al. [12] in their current meta-analysis found a high obesity rate among pediatric ALL survivors regardless of the treatment received. Although survivors who received CRT had a slightly higher BMI z-score than survivors who received chemotherapy alone, the difference was small, and nearly half of the studies did not support a difference in obesity rate after CRT treatment. In particular, for ALL survivors treated under modern protocols that do not involve CRT, a high prevalence of obesity was also observed. These results suggest that ALL survivors have an elevated risk of being overweight/obese regardless of CRT treatment.

Emerging evidence links testosterone deficiency to multiple cardiovascular risk factors including obesity, diabetes, hypertension, and altered lipid profiles, suggesting that gonadal function plays an important role in the regulation of metabolic homeostasis [13]. A low serum total testosterone level predicts the development of central obesity and the accumulation of intra-abdominal fat $[14,15]$. Similarly, low total and free testosterone as well as sex hormone-binding globulin (SHBG) levels are associated with an increased risk of developing metabolic syndrome, independent of age and obesity $[16,17]$.

The purpose of this study was to evaluate long-term effects of childhood ALL on body composition among adult male survivors. We specifically aimed to assess the role of gonadal dysfunction in the development of adiposity and to identify treatment-related risk factors predisposing to obesity among adult male survivors of childhood cancer.

\section{Patients and Methods}

\section{Study Population}

Adult male long-term ( $>10$ years) ALL survivors who were born in 1980 or earlier and had been treated at the Children's Hospital, Helsinki University Central Hospital, in 1970-1998 were identified through hospital records and invited to participate in a study assessing reproductive and bone health, related parameters as well as overall wellbeing, and marital, educational and employment status at adult age, as described earlier [18-20]. Of the total patient population $(\mathrm{n}=164), 75$ male long-term survivors were identified and contacted. Altogether, 51 subjects (68\%) consented and 24 did not respond to the invitation. All the study patients and control persons were Caucasians. Based on hospital records, the clinical characteristics of the 24 nonparticipants were comparable with those of the participants (data not shown). Control subjects ( 56 healthy males with no history of malignancy, aged between 24 and 36 years) matched by age and ethnic background were recruit- ed from occupational health services of Helsinki municipality area and Helsinki University Central Hospital. The Research Ethics Committee of Helsinki University Hospital approved the study; an informed written consent was obtained from all study subjects.

\section{Study Protocol}

The present study cohort comprised 49 ALL survivors and 55 controls who were clinically assessed, had available blood measurements relevant to testicular function, and body composition measured with dual-energy X-ray absorptiometry (DXA). A detailed history of the present health, physical exercise (number of active training sessions per week and daily hours of watching TV and videos), and ongoing endocrine replacement therapies and other medications was obtained by patient interview. Heights and weights were measured, and values were compared with the Finnish norms. The BMI was calculated as weight in kilograms divided by the square of height in meters $\left(\mathrm{kg} / \mathrm{m}^{2}\right)$. BMI data were available for 48 ALL survivors and 53 controls.

\section{Clinical Characteristics}

Data on the ALL survivors' previous medical history included a diagnosis of growth hormone deficiency, hypothyroidism, or hypogonadism, cumulative doses of irradiation and cytotoxic drugs as well as pubertal development including Tanner stages, and height and weight. Hypogonadism was defined as a testosterone level $<7 \mathrm{nmol} / \mathrm{l}$.

\section{Fat and Lean Mass Measurements by DXA}

DXA (Hologic ${ }^{\circledR}$ Discovery A, software version 12.3:3; Bedford, Mass., USA) was used. Body and trunk fat mass (kg), body and trunk lean mass, and percentage of body and trunk fat were measured.

\section{Biochemistry}

Blood samples were collected between 8 and 10 a.m. Samples were centrifuged, and serum levels of follicle-stimulating hormone (FSH), luteinizing hormone, inhibin $\mathrm{B}$, estradiol, testosterone, SHBG, insulin-like growth factor 1 (IGF-1), insulin-like growth factor binding protein 3 (IGFBP3), and leptin were measured in the laboratory of Helsinki University Central Hospital [18]. The serum free testosterone level was calculated from a previously validated equation [21]. Serum osteocalcin and carboxylated osteocalcin, potential bone-derived regulators of energy metabolism [22], and testosterone [23] were determined as previously described using a two-site immunoassay [24]. Serum adiponectin levels were determined with Quantikine Human Adiponectin Immunoassay (R\&D Systems, Minneapolis, Minn., USA).

\section{Statistical Analysis}

Simple regression analysis, Student's unpaired t test (normally distributed variables), the Mann-Whitney U test (non-normally distributed variables), and the $\chi^{2}$ test were used for statistical analysis (SPSS Statistics), as appropriate, to determine the relationship between whole body and trunk fat mass, whole body and trunk lean mass, percentages of whole body and trunk fat mass, and specified clinical variables, and to analyze differences in these parameters between subgroups. Since there was a significant difference in height between the groups and an interaction between height and parameters of body composition, comparisons were adjusted for height. A p value $<0.05$ was considered statistically significant. 


\section{Results}

\section{Patient Characteristics}

The 49 male ALL survivors were assessed at a median age of 29 years (range 25-38). Their median age at ALL diagnosis was 5 years. The median follow-up since the end of ALL therapy was 20 years (range 10-29; table 1). Seventy-three percent of the survivors had received CRT, 35\% testicular irradiation, and 49\% cyclophosphamide as part of their ALL treatment regimen. Hypogonadism had been diagnosed in 20 ALL survivors (41\%); 16 of them $(80 \%)$ had received testicular irradiation, 19 (95\%) CRT, and 10 (50\%) cyclophosphamide. At the time of assessment, 14 of the hypogonadal survivors had adequate substitution with testosterone while 6 (30\%) had serum testosterone levels $<7 \mathrm{nmol} / \mathrm{l}$ and were regarded as noncompliant to testosterone replacement therapy. None of the ALL survivors or controls were receiving growth hormone or thyroid hormone therapy at the time of the study or had been earlier diagnosed to have growth hormone deficiency or hypothyroidism. The median age of the 55 male controls was 30 years (range 24-36). The ALL survivors were significantly shorter that the controls (median 176.0 vs. 180.5 $\mathrm{cm} ; \mathrm{p}=0.007)$ but their weights (75.5 vs. $82.0 \mathrm{~kg})$ and BMIs (24.3 vs. 25.1$)$ were similar ( $\mathrm{p}>0.05$; table 2 ). The ALL survivors with a history of CRT $(\mathrm{n}=36)$ were significantly shorter (175.3 vs. $182.3 \mathrm{~cm} ; \mathrm{p}=0.003)$ than the ALL survivors without a history of CRT. The heights of those without CRT were not different from the male controls $(\mathrm{p}=0.29)$. The ALL survivors were significantly less active than the controls (mean physical training 0.9 vs. $2.0 \mathrm{~h} /$ week; $\mathrm{p}<0.001$ ) and spent significantly more time watching TV and videos (on average 3.0 vs. $2.1 \mathrm{~h} /$ day; $\mathrm{p}=0.005$ ).

No difference in the number of overweight subjects (BMI $\geq 25$ ) between ALL survivors and controls were detected. Seven of 48 (15\%) ALL survivors and 5 of the 53 $(9 \%)$ controls were obese $(\mathrm{BMI} \geq 30 ; \mathrm{p}=0.42)$. Of these 7 obese survivors, 4 (57\%) had received testicular irradiation, 6 (86\%) CRT, and 3 (43\%) were using testosterone substitution, while the corresponding numbers among the 41 nonobese ALL survivors were $13(32 \%$; $\mathrm{p}=0.19)$, 23 (56\%; $\mathrm{p}=0.48)$, and $12(29 \% ; \mathrm{p}=0.47)$.

\section{Biochemistry}

There were significant differences between the ALL survivors and the male controls in hormonal parameters and testicular function, as reported previously [18]. The ALL survivors had significantly higher FSH levels, lower testosterone levels, and lower inhibin B levels but there was no difference in SHBG levels when compared to con-
Table 1. Characteristics of the 49 male long-term ALL survivors

\begin{tabular}{|c|c|c|c|}
\hline Characteristics & $\begin{array}{l}\text { Median } \\
\text { (range) }\end{array}$ & $\mathrm{n}$ & $\begin{array}{l}\text { Survivors, } \\
\%\end{array}$ \\
\hline Age at study, years & $29(25-38)$ & & \\
\hline Age at diagnosis & $5(1-15)$ & & \\
\hline$<5$ years & & 23 & 47 \\
\hline $5-10$ years & & 16 & 33 \\
\hline$>10$ years & & 10 & 20 \\
\hline Age at the end of therapy & $8(3-17)$ & & \\
\hline$<5$ years & & 2 & 4 \\
\hline $5-10$ years & & 32 & 65 \\
\hline$>10$ years & & 15 & 31 \\
\hline Time since the end of therapy & $20(10-29)$ & & \\
\hline $10-15$ years & & 11 & 22 \\
\hline $16-20$ years & & 15 & 31 \\
\hline $21-30$ years & & 23 & 47 \\
\hline Cranial irradiation & & 36 & 73 \\
\hline $18 \mathrm{~Gy}$ & & 5 & \\
\hline $24-26 \mathrm{~Gy}$ & & 30 & \\
\hline $48 \mathrm{~Gy}$ & & 1 & \\
\hline Spinal irradiation 6 Gy & & 1 & 2 \\
\hline Testicular irradiation & & 17 & 35 \\
\hline $10 \mathrm{~Gy}$ & & 2 & \\
\hline $24 \mathrm{~Gy}$ & & 15 & \\
\hline Cyclophosphamide & & 24 & 49 \\
\hline $1.2-3.0 \mathrm{~g} / \mathrm{m}^{2}$ & & 7 & \\
\hline $4.6-9.9 \mathrm{~g} / \mathrm{m}^{2}$ & & 13 & \\
\hline $25.0-29.0 \mathrm{~g} / \mathrm{m}^{2}$ & & 4 & \\
\hline Diagnosis of testosterone deficien & & 20 & 41 \\
\hline On replacement & & 14 & \\
\hline No replacement & & 6 & \\
\hline
\end{tabular}

trols (table 3). The serum testosterone level was $<7.0$ $\mathrm{nmol} / \mathrm{l}$ in 6 and $7-9 \mathrm{nmol} / \mathrm{l}$ in 4 ALL survivors while none of the controls had values $<7.0 \mathrm{nmol} / 1$ and 2 had values of 7-9 nmol/l. Serum IGF-1 levels were similar, but IGFBP3 levels were lower in the ALL survivors $(\mathrm{p}<0.001)$.

Serum leptin levels were higher $(p=0.012)$ in the ALL survivors than in the controls (table 3 ). Similarly, significantly higher levels of serum adiponectin were observed among ALL survivors $(\mathrm{p}=0.003)$ while no difference in the levels of serum osteocalcin and carboxylated osteocalcin were detected between the groups (table 3). No correlations between serum testosterone and serum adiponectin or serum leptin levels were detected between ALL survivors and controls.

Survivors with a BMI $\geq 30$ were more severely obese when compared with the obese controls. Their mean body fat mass was $33 \mathrm{~kg}$ and the mean trunk fat mass 16 $\mathrm{kg}$ as compared with 23 and $12 \mathrm{~kg}$, respectively (table 4). Serum testosterone and SHBG levels were significantly 
Table 2. Anthropometry and body composition findings in the 49 male ALL survivors and 55 healthy controls

\begin{tabular}{|c|c|c|c|c|c|}
\hline \multirow[t]{2}{*}{ Characteristics } & \multicolumn{2}{|c|}{ ALL survivors } & \multicolumn{2}{|l|}{ Controls } & \multirow[t]{2}{*}{$\mathrm{p}$ value } \\
\hline & median & range & median & range & \\
\hline Age, years & 29 & $25-38$ & 30 & $24-36$ & 0.22 \\
\hline Height, cm & 176.0 & $163.0-193.5$ & 180.0 & $167.5-194.0$ & 0.007 \\
\hline Weight, kg & 75.5 & $48.5-118.0$ & 82.0 & $58.0-114.0$ & 0.10 \\
\hline $\mathrm{BMI}^{1}$ & 24.3 & $18.3-35.9$ & 25.1 & $19.4-34.8$ & 0.47 \\
\hline Body fat mass, kg & 15.7 & $7.4-37.3$ & 15.5 & $6.2-30.9$ & 0.12 \\
\hline Trunk fat mass, kg & 6.8 & $2.7-18.0$ & 6.5 & $2.4-17.9$ & 0.22 \\
\hline$\%$ body fat mass & 21.0 & $12.1-35.6$ & 18.3 & $9.5-33.8$ & 0.019 \\
\hline$\%$ trunk fat mass & 19.8 & $10.5-35.1$ & 17.3 & $8.2-33.3$ & 0.05 \\
\hline Body lean mass, kg & 59.5 & $39.2-83.5$ & 64.4 & $48.9-83.4$ & $<0.001$ \\
\hline Trunk lean mass, kg & 27.0 & $18.7-40.5$ & 30.4 & $22.1-40.7$ & $<0.001$ \\
\hline
\end{tabular}

All $\mathrm{p}$ values for parameters of body composition are adjusted for height.

${ }^{1}$ Number of observations was 48 for survivors and 53 for controls.

Table 3. Biochemical findings in the 49 ALL survivors and 55 controls

\begin{tabular}{|c|c|c|c|c|c|}
\hline \multirow[t]{2}{*}{ Parameters } & \multicolumn{2}{|c|}{ ALL survivors } & \multicolumn{2}{|c|}{ Controls } & \multirow[t]{2}{*}{$\mathrm{p}$ value } \\
\hline & median & range & median & range & \\
\hline Testosterone, nmol/l & 14.5 & $0.40-61.8$ & 18.5 & $7.1-32.6$ & 0.001 \\
\hline Estradiol, nmol/1 & 0.08 & $0.03-0.27$ & 0.07 & $0.05-0.25$ & 0.27 \\
\hline Inhibin B, ng/l & 71 & $10-287$ & 158 & $74-307$ & $<0.001$ \\
\hline $\mathrm{FSH}, \mathrm{IU} / \mathrm{l}$ & 5.0 & $0.9-55.5$ & 3.2 & $0.9-11.4$ & 0.002 \\
\hline Luteinizing hormone, IU/l & 4.2 & $0.0-22.8$ & 3.3 & $1.8-8.1$ & 0.08 \\
\hline SHBG, nmol/l & 31.0 & $9.0-76.0$ & 32.5 & $13.0-70.0$ & 0.26 \\
\hline Leptin, $\mu \mathrm{g} / \mathrm{l}$ & 4.8 & $0.6-22.2$ & 2.5 & $0.6-15.6$ & 0.012 \\
\hline Carboxylated osteocalcin, $\mu \mathrm{g} / \mathrm{l}$ & 8.45 & $4.41-18.0$ & 8.44 & $5.19-21.8$ & 0.93 \\
\hline Osteocalcin, $\mu \mathrm{g} / \mathrm{l}$ & 9.13 & $4.89-18.67$ & 8.53 & $5.45-20.7$ & 0.61 \\
\hline Adiponectin, mg/l & 6.7 & $2.7-19.0$ & 4.6 & $1.7-15.7$ & 0.003 \\
\hline Adiponectin $^{1}, \mu \mathrm{g} / \mathrm{l} / \mathrm{BMI}$ & 265.3 & $92-845$ & 179.5 & $61-703$ & 0.007 \\
\hline Leptin $^{1}$, ng/l/BMI & 190.2 & $24.6-683.6$ & 109.0 & $25.5-555.5$ & 0.007 \\
\hline IGF-1, nmol/1 & 23 & $6-49$ & 23 & $12-36$ & 0.87 \\
\hline IGFBP3, mg/l & 3.2 & $2.3-5.0$ & 4.3 & $3.1-6.1$ & $<0.001$ \\
\hline
\end{tabular}

${ }^{1}$ Number of observations was 48 for survivors and 53 for controls.

lower among obese survivors when compared with nonobese survivors (table 4). This difference was not seen in the control group. Both obese survivors and controls displayed significantly higher serum leptin levels when compared with nonobese survivors and controls, respectively (table 4).

\section{DXA Findings}

The body composition findings are presented in table 2. The ALL survivors had significantly lower trunk lean mass ( $\mathrm{p}=0.002)$ and body lean mass $(\mathrm{p}=0.003)$, and higher percentages of trunk fat mass $(p=0.009)$ and body fat mass $(p=0.004)$. The differences between the groups remained significant even when adjusted for height (table 2).

The BMI correlated significantly $(\mathrm{p}<0.001)$ with all DXA parameters including body fat $(\mathrm{r}=0.93)$, trunk fat $(\mathrm{r}=0.93)$, percent body fat $(\mathrm{r}=0.83)$, percent trunk fat $(\mathrm{r}=0.87)$, and trunk lean $(\mathrm{r}=0.68)$ and body lean $(\mathrm{r}=$ 0.72 ) mass (table 5). In survivors and controls, SHBG as- 
Table 4. Lean and fat body mass and biochemical findings in obese (BMI $\geq 30)$ and nonobese ALL survivors and controls

\begin{tabular}{|c|c|c|c|c|c|c|c|c|c|c|}
\hline Parameters & \multicolumn{2}{|c|}{$\mathrm{BMI}<30(\mathrm{n}=41)$} & \multicolumn{2}{|c|}{$\mathrm{BMI} \geq 30(\mathrm{n}=7)$} & $\mathrm{p}$ & \multicolumn{2}{|c|}{$\mathrm{BMI}<30(\mathrm{n}=48)$} & \multicolumn{2}{|c|}{$\mathrm{BMI} \geq 30(\mathrm{n}=5)$} & $\mathrm{p}$ \\
\hline Total fat mass, kg & 15.4 & $7.4-24.0$ & 33.1 & $28.5-37.1$ & $<0.001$ & 15.2 & $6.2-30.4$ & 23.5 & $18.6-30.9$ & 0.010 \\
\hline$\%$ total fat & 20.1 & $12.1-27.3$ & 31.5 & $27.4-35.6$ & $<0.001$ & 18.1 & $9.5-33.8$ & 22.2 & $18.3-26.7$ & 0.079 \\
\hline Leptin, $\mu g / 1$ & 4.8 & $0.6-14.3$ & 18.2 & $13.0-22.2$ & $<0.001$ & 4.1 & $0.6-15.6$ & 8.6 & $2.1-14.9$ & 0.043 \\
\hline Adiponectin, mg/l & 7.2 & $2.7-19.0$ & 6.2 & $3.1-12.2$ & 0.393 & 5.6 & $1.7-15.7$ & 3.5 & $2.5-4.6$ & 0.081 \\
\hline Osteocalcin, $\mu \mathrm{g} / \mathrm{l}$ & 8.9 & $4.9-18.7$ & 10.5 & $7.3-16.0$ & 0.181 & 9.1 & $5.5-20.7$ & 9.3 & $7.4-11.3$ & 0.430 \\
\hline Testosterone, nmol/l & 16.5 & $1.4-61.8$ & 9.0 & $0.4-19.8$ & 0.031 & 20.3 & $7.1-32.6$ & 15.8 & $10.6-21.1$ & 0.145 \\
\hline $\mathrm{SHBG}, \mathrm{nmol} / \mathrm{l}$ & 34.9 & $9.0-76.0$ & 20.4 & $9.0-39.0$ & 0.010 & 37.3 & $13.0-70.0$ & 25.6 & $19.0-33.0$ & 0.077 \\
\hline LH, IU/l & 5.3 & $0.0-22.8$ & 4.0 & $0.3-9.2$ & 0.491 & 3.6 & $1.9-8.1$ & 3.6 & $1.8-5.8$ & 0.848 \\
\hline
\end{tabular}

LH = Luteinizing hormone

sociated $(\mathrm{p}<0.01)$ with body fat mass and percent body fat but not with body or trunk lean mass (table 5). In the control group, percent body fat correlated with serum levels of osteocalcin $(\mathrm{p}=0.025)$ and testosterone $(\mathrm{p}=$ 0.03), while among ALL survivors, these correlations were lacking (table 5). No correlation between DXA and parameters of testicular endocrine function, other than SHBG, were detected (table 5). No correlation between DXA parameters and age at the onset of leukemia or the time elapsed from the leukemia therapy was detected.

When the group of ALL survivors was divided according to treatment-related parameters, no differences in serum leptin, adiponectin or osteocalcin levels, BMI, trunk fat mass, or lean mass parameters were observed between survivors who had received CRT and those without CRT, or between survivors who had received gonadotoxic doses of cyclophosphamide $\left(>20 \mathrm{~g} / \mathrm{m}^{2}\right)$ or testicular irradiation and those without such therapy. No associations with serum testosterone levels were detected for these parameters.

\section{Discussion}

We carried out a cross-sectional study to evaluate body composition parameters using DXA and their clinical and biochemical determinants in long-term male ALL survivors at young adult age (25-38 years) on average 20 years after the end of ALL therapy. The 49 ALL survivors had significantly higher percent fat mass at all measured sites than the 55 male controls without a history of cancer. There was no difference between body fat and trunk fat mass, which is possibly associated with the smaller size of the ALL survivors. The median heights of ALL survivors were lower, but their median weight and BMI values were not different from controls. Present observations support that the estimation of body adiposity among male ALL long-term survivors needs to be determined by other methods than by weight and BMI. The DXA-derived percentage of body fat was shown to more accurately reflect true body adiposity, supporting the earlier observation of Blijdorp et al. [25].

ALL survivors had lower IGFBP3 levels, but their IGF1 levels were similar to the controls. This may reflect the inferior growth hormone status in the ALL survivors. We found no correlation between absolute body fat mass and IGF-1. Instead, body and trunk lean mass was lower among ALL survivors and correlated significantly with serum IGF levels in the control group. This is in line with previous observations showing that an inferior growth hormone status affects body composition by decreasing lean body mass [10].

We observed increased levels of leptin in male ALL survivors, in line with the observed increased adiposity. Previously increased leptin levels have been demonstrated among female survivors treated with and without CRT $[26,27]$ and, to a lesser extent, in male ALL survivors with CRT [28]. Serum leptin levels are known to increase soon 
Table 5. Correlations of body composition values with measured variables in 49 male ALL survivors and 55 controls

\begin{tabular}{|c|c|c|c|c|}
\hline \multirow[t]{2}{*}{ Parameters/variables } & \multicolumn{2}{|c|}{ ALL survivors } & \multicolumn{2}{|c|}{ Controls } \\
\hline & $\mathrm{r}$ & $\mathrm{p}$ & $\mathrm{r}$ & $\mathrm{p}$ \\
\hline \multicolumn{5}{|l|}{ Body fat mass } \\
\hline $\mathrm{BMI}^{1}$ & 0.93 & $<0.001$ & 0.81 & $<0.001$ \\
\hline Leptin & 0.89 & $<0.001$ & 0.84 & $<0.001$ \\
\hline Adiponectin & -0.15 & 0.33 & 0.06 & 0.66 \\
\hline Osteocalcin & -0.01 & 0.97 & -0.25 & 0.08 \\
\hline Testosterone & -0.28 & 0.07 & -0.27 & 0.06 \\
\hline SHBG & -0.41 & 0.005 & -0.37 & 0.007 \\
\hline FSH & -0.02 & 0.89 & -0.19 & 0.18 \\
\hline Inhibin B & -0.19 & 0.23 & -0.08 & 0.57 \\
\hline IGF-1 & 0.06 & 0.71 & 0.16 & 0.25 \\
\hline IGFBP3 & 0.13 & 0.38 & 0.19 & 0.19 \\
\hline \multicolumn{5}{|l|}{ Body lean mass } \\
\hline $\mathrm{BMI}^{1}$ & 0.72 & $<0.001$ & 0.82 & $<0.001$ \\
\hline Leptin & 0.45 & 0.002 & 0.23 & 0.10 \\
\hline Adiponectin & -0.16 & 0.32 & -0.16 & 0.27 \\
\hline Osteocalcin & -0.08 & 0.63 & 0.06 & 0.64 \\
\hline Testosterone & -0.18 & 0.25 & -0.03 & 0.82 \\
\hline SHBG & -0.18 & 0.23 & -0.10 & 0.48 \\
\hline FSH & -0.14 & 0.35 & 0.05 & 0.70 \\
\hline Inhibin B & -0.01 & 0.94 & -0.25 & 0.08 \\
\hline IGF-1 & -0.01 & 0.94 & 0.28 & 0.040 \\
\hline IGFBP3 & 0.27 & 0.08 & 0.16 & 0.26 \\
\hline \multicolumn{5}{|l|}{$\%$ body fat } \\
\hline $\mathrm{BMI}^{1}$ & 0.83 & $<0.001$ & 0.63 & $<0.001$ \\
\hline Leptin & 0.89 & $<0.001$ & 0.86 & $<0.001$ \\
\hline Adiponectin & -0.13 & 0.41 & 0.15 & 0.29 \\
\hline Osteocalcin & 0.08 & 0.61 & -0.32 & 0.025 \\
\hline Testosterone & 0.23 & 0.12 & -0.30 & 0.030 \\
\hline SHBG & -0.43 & 0.003 & -0.39 & 0.004 \\
\hline FSH & 0.62 & 0.62 & -0.24 & 0.08 \\
\hline Inhibin B & -0.23 & 0.13 & 0.02 & 0.91 \\
\hline IGF-1 & 0.10 & 0.52 & 0.09 & 0.50 \\
\hline IGFBP3 & 0.07 & 0.64 & 0.15 & 0.29 \\
\hline
\end{tabular}

${ }^{1}$ Number of observations was 48 for survivors and 53 for controls.

after ALL diagnosis [29] and remain high during the first year after chemotherapy withdrawal [11]. The present observation confirms long-term persistence of hyperleptinemia in male ALL survivors [28]. Normally, leptin acts by decreasing appetite and food intake which leads to a decrease in BMI. Obese individuals exhibit high levels of leptin expression in adipose tissue and have elevated circulating leptin levels which fail to reduce excess adiposity [30]. In the present study, very high levels of leptin were observed among obese ALL survivors, and even more remarkable increases in leptin levels were observed when the values were adjusted for the BMI. It has been shown that hypogonadal men have increased leptin levels and that testosterone substitution therapy can normalize elevated serum leptin levels [31]. The mechanisms by which testosterone reduces leptin levels are uncertain but may include the capacity of testosterone to reduce adipose tissue mass [32]. In the present study, no correlation between serum levels of testosterone and leptin or BMI was shown.

Serum levels of adiponectin were higher in the survivors than in the controls. Adiponectin is known to inversely correlate with body fat [33]. In this study, no association between adiponectin, body fat mass, body lean mass, or percent body fat was observed. If adjusted for BMI, adiponectin levels showed an even more remarkable difference between survivors and controls. Earlier studies have not found differences in the levels of adiponectin between ALL survivors and controls. These high adiponectin levels in male survivors with increased percent body fat are contradictory to the known role of adiponectin as a factor that increases insulin sensitivity and decreases fat mass [33]. Previous studies indicate that serum concentrations of adiponectin in hypogonadal men, including those with Klinefelter syndrome, are higher than those in eugonadal men, and a significant reduction is observed after testosterone replacement therapy [34]. On the other hand, similar to our findings, some previous studies found no correlation between testosterone and adiponectin $[35,36]$. The increased level of serum adiponectin among ALL survivors may reflect the partial Leydig cell insufficiency. A significant part of the presently studied survivors had received cancer treatments that potentially damage Leydig cells. The significance of adiponectin for body composition among adult male leukemia survivors remains unclear and needs to be evaluated in further studies.

A low serum testosterone level is known to be a significant risk factor for adiposity [13-15]. Therefore, it is important to ensure proper testosterone replacement therapy and follow the compliance in adult ALL survivors with testosterone deficiency. In the present cohort, altogether 20 of the ALL males had been diagnosed with hypogonadism during puberty. Most of them were on sufficient testosterone replacement therapy at the study visit, but 6 males (12\% of the cohort) had untreated hypogonadism with a low testosterone concentration and increased gonadotrophin values. Despite a substantial number of hypogonadal survivors, we were not able to detect any correlation between the serum testicular endocrine markers testosterone, FSH, or inhibin B and any of 
the DXA-derived body composition parameters among ALL men. Instead, low serum SHBG levels associated significantly with increased body fat mass and percent body fat in both survivors and controls, in line with the suggested independent role of serum SHBG concentration as an indicator of metabolic syndrome, including central adiposity [37].

Severe obesity $(B M I \geq 30)$ but not overweight (BMI $\geq 25$ ) was more frequent among ALL survivors. Obese ALL survivors showed adverse hormonal parameters and decreased testicular function, including lower serum testosterone and decreased serum inhibin B levels when compared to nonobese survivors. Altogether, 60\% of obese survivors had received testicular irradiation compared with $29 \%$ of the nonobese survivors. The incidence of CRT (86 vs. 56\%) was also higher among obese ALL survivors. The observed association with gonadotoxic testicular irradiation combined with CRT supports the idea that obesity is a consequence rather than an independent determinant of decreased gonadal function [38] in long-term survivors of ALL. Testicular irradiation that induces overt Leydig cell damage with the need of testosterone replacement therapy, especially when combined with CRT, can increase the risk of obesity among longterm survivors of childhood ALL.

The high prevalence of overweight $(\mathrm{BMI} \geq 25)$ in the control group (51\%) is in line with a previous longitudinal population-based follow-up study which shows that the prevalence of overweight among Finnish young men in the age group 19-39 years varies between 25 and 52\%, and that of obesity (BMI $\geq 30)$ between 9 and $13 \%$ [39, 40]. According to these reports, the control subjects of the present study represent the general population of young men in Finland.

Our study suffers from some limitations. We conducted a cross-sectional analysis, and since the majority of survivors had received cranial irradiation, the effect of gonadotoxic antileukemia therapy on body composition could not be studied separately from the effects of CRT. The high proportion of survivors with prophylactic cranial and testicular irradiation reflects the early era of curative ALL therapy in the 70 s and 80 s, which differs from ALL therapy applied today. Evaluations were further compromised by the relatively small sample size and small number of obese survivors. Further, the patients and subjects were matched for age, sex, and ethnicity but not for BMI, which would have allowed us to better compare differences in body composition. Additionally, we do not have measures of body fat at ALL diagnosis in this survivor cohort.

In conclusion, our study shows that at young adulthood (mean age 29 years), long-term male ALL survivors have significantly higher percentages of body and trunk fat mass when compared with age-matched controls. Potential indicators of increased adiposity included increased leptin and low SHBG levels. The other serum testicular endocrine markers did not correlate with body adiposity. The increased adiposity in ALL survivors requires surveillance for possible other cardiovascular risk factors.

\section{References}

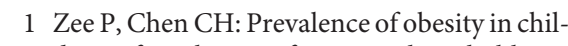
dren after therapy for acute lymphoblastic leukemia. Am J Pediatr Hematol Oncol 1986; 8:294-299.

-2 Sainsbury CPQ, Newcombe RG, Hughes IA: Weight gain and height velocity during prolonged first remission from ALL. Arch Dis Child 1985;60:832-836.

3 Warner JT, Evans WD, Webb DK, Gregory JW: Body composition of long-term survivors of acute lymphoblastic leukaemia. Med Pediatr Oncol 2002;38:165-172.

4 Marinovic D, Dorgeret S, Lescoeur B, Alberti C, Noel M, Czernichow P, Sebag G, Vilmer E, Leger J: Improvement in bone mineral density and body composition in survivors of childhood acute lymphoblastic leukemia: a 1 -year prospective study. Pediatrics 2005;116: 102-108.
5 Oeffinger KC, Buchanan GR, Eshelman DA, Denke MA, Andrews TC, Germak JA, Tomlinson GE, Snell LE, Foster BM: Cardiovascular risk factors in young adult survivors of childhood acute lymphoblastic leukemia. J Pediatr Hematol Oncol 2001;23:424-430.

-6 Kourti M, Tragiannidis A, Makedou A, Papageorgiou T, Rousso I, Athanassiadou F: Metabolic syndrome in children and adolescents with acute lymphoblastic leukemia after the completion of chemotherapy. J Pediatr Hematol Oncol 2005;27:499-501.

7 Mertens AC, Yasui Y, Neglia JP, Potter JD, Nesbit ME Jr, Ruccione K, Smithson WA, Robison LL: Late mortality experience in fiveyear survivors of childhood and adolescent cancer: the Childhood Cancer Survivor Study. J Clin Oncol 2001;19:3163-3172.
-8 Janiszewski PM, Oeffinger KC, Church TS, Dunn AL, Eshelman DA, Victor RG, Brooks S, Turoff AJ, Sinclair E, Murray JC, Bashore L, Ross R: Abdominal obesity, liver fat, and muscle composition in survivors of childhood acute lymphoblastic leukemia. J Clin Endocrinol Metab 2007;92:3816-3821.

9 Gurney JG, Ness KK, Sibley SD, O’Leary M, Dengel DR, Lee JM, Youngren NM, Glasser SP, Baker KS: Metabolic syndrome and growth hormone deficiency in adult survivors of childhood acute lymphoblastic leukemia. Cancer 2006;107:1303-1312.

10 Link K, Moell C, Garwicz S, Cavallin-Stahl E, Bjork J, Thilen U, Ahren B, Erfurth EM: Growth hormone deficiency predicts cardiovascular risk in young adults treated for acute lymphoblastic leukemia in childhood. J Clin Endocrinol Metab 2004;89:5003-5012. 
-11 Arguelles B, Barrios V, Buno M, Madero L, Argente J: Anthropometric parameters and their relationship to serum growth hormonebinding protein and leptin levels in children with acute lymphoblastic leukemia: a prospective study. Eur J Endocrinol 2000;143. 243-250.

12 Zhang FF, Kelly MJ, Saltzman E, Must A, Roberts SB, Parsons SK: Obesity in pediatric ALL survivors: a meta-analysis. Pediatrics 2014;133:704-715.

13 Muraleedharan V, Hugh Jones T: Testosterone and mortality. Clin Endocrinol (Oxf) 2014;81:477-487.

14 Haffner SM, Valdez RA, Stern MP, Katz MS: Obesity, body fat distribution and sex hormones in men. Int J Obes Relat Metab Disord 1993; 17:643-649.

-15 Nielsen TL, Hagen C, Wraae K, Brixen K, Petersen PH, Haug E, Larsen R, Andersen M: Visceral and subcutaneous adipose tissue assessed by magnetic resonance imaging in relation to circulating androgens, sex hormonebinding globulin, and luteinizing hormone in young men. J Clin Endocrinol Metab 2007;92: 2696-2705.

- 16 Kupelian V, Page ST, Araujo AB, Travison TG, Bremner WJ, McKinlay JB: Low sex hormone-binding globulin, total testosterone, and symptomatic androgen deficiency are associated with development of the metabolic syndrome in nonobese men. J Clin Endocrinol Metab 2006;91:843-850.

17 Muller M, Grobbee DE, den Tonkelaar I, Lamberts SW, van der Schouw YT: Endogenous sex hormones and metabolic syndrome in aging men. J Clin Endocrinol Metab 2005; 90:2618-2623.

18 Jahnukainen K, Heikkinen R, Henriksson M, Cooper TG, Puukko-Viertomies LR, Mäkitie $\mathrm{O}$ : Semen quality and fertility in adult longterm survivors of childhood acute lymphoblastic leukemia. Fertil Steril 2011;96:837842.

19 Mäkitie O, Heikkinen R, Toiviainen-Salo S, Henriksson M, Puukko-Viertomies LR, Jahnukainen K: Long-term skeletal consequences of childhood acute lymphoblastic leukemia in adult males: a cohort study. Eur J Endocrinol 2013;168:281-288.

20 Gunn ME, Lähteenmäki PM, Puukko-Viertomies LR, Henriksson M, Heikkinen R, Jahnukainen K: Potential gonadotoxicity of treatment in relation to quality of life and mental well-being of male survivors of childhood acute lymphoblastic leukemia. J Cancer Surviv 2013;7:404-412.
21 Vermeulen A, Verdonck L, Kaufman JM: A critical evaluation of simple methods for the estimation of free testosterone in serum. J Clin Endocrinol Metab 1999;10:3666-3672.

-22 Yeap BB, Chubb SA, Flicker L, McCaul KA, Ebeling PR, Beilby JP, Norman PE: Reduced serum total osteocalcin is associated with metabolic syndrome in older men via waist circumference, hyperglycemia, and triglyceride levels. Eur J Endocrinol 2010;163:265272.

23 Kirmani S, Atkinson EJ, Melton LJ 3rd, Riggs BL, Amin S, Khosla S: Relationship of testosterone and osteocalcin levels during growth. J Bone Miner Res 2011;26:2212-2216.

24 Paldánius PM, Ivaska KK, Hovi P, Andersson S, Väänänen HK, Kajantie E, Mäkitie O: The effect of oral glucose tolerance test on serum osteocalcin and bone turnover markers in young adults. Calcif Tissue Int 2010;90:9095.

25 Blijdorp K, van den Heuvel-Eibrink MM, Pieters R, Boot AM, Delhanty PJ, van der Lely AJ, Neggers SJ: Obesity is underestimated using body mass index and waist-hip ratio in long-term adult survivors of childhood cancer. PLoS One 2012;7:e43269.

26 Karaman S, Ercan O, Yildiz I, Bolayirli M, Celkan T, Apak H, Ozkan A, Onal H, Canbolat A: Late effects of childhood ALL treatment on body mass index and serum leptin levels. J Pediatr Endocrinol Metab 2010;23:669-674.

$\checkmark 27$ Kohler JA, Moon RJ, Wright S, Willows E, Davies JH: Increased adiposity and altered adipocyte function in female survivors of childhood acute lymphoblastic leukaemia treated without cranial radiation. Horm Res Paediatr 2011;75:433-440.

28 Tonorezos ES, Vega GL, Sklar CA, Chou JF, Moskowitz CS, Mo Q, Church TS, Ross R, Janiszewski PM, Oeffinger KC: Adipokines, body fatness, and insulin resistance among survivors of childhood leukemia. Pediatr Blood Cancer 2012;58:31-36.

29 Wallace AM, Tucker P, Williams DM, Hughes IA, Ahmed SF: Short-term effects of prednisolone and dexamethasone on circulating concentrations of leptin and sex hormone-binding globulin in children being treated for acute lymphoblastic leukaemia. Clin Endocrinol (Oxf) 2003;58:770-776.

30 Blüher S, Mantzoros CS: Leptin in humans: lessons from translational research. Am J Clin Nutr 2009;89:991S-997S.

31 Jockenhövel, Blum WF, Vogel E, Englaro P, Müller-Wieland D, Reinwein D, Rascher W, Krone W: Testosterone substitution normalizes elevated serum leptin levels in hypogonadal men. J Clin Endocrinol Metab 1997;82: 2510-2513.
32 Kapoor D, Clarke S, Stanworth R, Channer KS, Jones TH: The effect of testosterone replacement therapy on adipocytokines and Creactive protein in hypogonadal men with type 2 diabetes. Eur J Endocrinol 2007;156: 595-602.

33 Gawa-Yamauchi M, Moss KA, Bovenkerk JE, Shankar SS, Morrison CL, Lelliott CJ, VidalPuig A, Jones R, Considine RV: Regulation of adiponectin expression in human adipocytes: effects of adiposity, glucocorticoids, and tumor necrosis factor alpha. Obes Res 2005;13: 662-669.

34 Lanfranco F, Zitzmann M, Simoni M, Nieschlag E: Serum adiponectin levels in hypogonadal males: influence of testosterone replacement therapy. Clin Endocrinol (Oxf) 2004;60:500-507.

-35 Tsujimura A, Takada S, Matsuoka Y, Nakayama J, Takao T, Miyagawa Y, Sonoda M, Nishizawa H, Iwahashi H, Funahashi T, Nonomura N, Okuyama A: Adiponectin and testosterone in patients with symptoms of lateonset hypogonadism: is there a link? Int J Urol 2009;16:830-835.

36 Tuna MM, Doğan BA, Karakılıç E, Arduç A, Işık S, Yılmaz FM, Topçuoğlu C, Berker D, Güler S: Evaluation of adipocytokine levels and vascular functions in young aged to middle aged men with idiopathic hypogonadotrophic hypogonadism. Neuro Endocrinol Lett 2014;35:640-644.

37 Bhasin S, Jasjua GK, Pencina M, D’Agostino R Sr, Coviello AD, Vasan RS, Travison TG: Sex hormone-binding globulin, but not testosterone, is associated prospectively and independently with incident metabolic syndrome in men: the Framingham Heart Study. Diabetes Care 2011;34:2464-2470.

38 Blijdorp K, van Dorp W, Laven JS, Pieters R, de Jong FH, Pluijm SM, van der Lely AJ, van den Heuvel-Eibrink MM, Neggers SJ: Obesity independently influences gonadal function in very long-term adult male survivors of childhood cancer. Obesity 2014;22:1896-1903.

39 Nissinen K, Mikkilä V, Männistö S, LahtiKoski M, Räsänen L, Viikari J, Raitakari OT: Sweets and sugar-sweetened soft drink intake in childhood in relation to adult BMI and overweight. The Cardiovascular Risk in Young Finns Study. Public Health Nutr 2009; 12:2018-2026.

40 Hagnäs MP, Cederberg H, Mikkola I, Ikäheimo TM, Jokelainen J, Laakso M, Härkönen P, Peitso A, Rajala U, Keinänen-Kiukaanniemi $S$ : Reduction in metabolic syndrome among obese young men is associated with exerciseinduced body composition changes during military service. Diabetes Res Clin Pract 2012; 98:312-319. 